\title{
INFLUÊNCIA DO ÁCIDO SULFÚRICO ASSOCIADO COM FUNGICIDA SOBRE A GERMINAÇÃO E A CONTAMINAÇÃO IN VITRO DE Lychnophora pohlii Sch.Bip.
}

\author{
Ana Caroline Macedo de Castro 1 \\ Clara Almeida Guerra ${ }^{2}$ \\ Miranda Titon ${ }^{3}$
}

\begin{abstract}
Resumo: Lychnophora pohlii possui propriedades medicinais e devido sua intensa exploração encontra-se na lista de espécies ameaçadas de extinção. A micropropagação tem sido uma importante ferramenta para a propagação de espécies que apresentam limitações na propagação convencional, ameaçadas de extinção etc. Objetivou-se estabelecer uma metodologia de germinação in vitro de L. pohlii. O experimento foi instalado em delineamento inteiramente casualizado, em esquema fatorial ( $2 \times 2$ ), sendo os tratamentos formados pela combinação entre a imersão das sementes em ácido sulfúrico $\left(\mathrm{H}_{2} \mathrm{SO}_{4}\right)$ por 10 e 20 minutos e utilização ou não de fungicida. Os tratamentos sem fungicida e com fungicida por 20 minutos em $\mathrm{H}_{2} \mathrm{SO}_{4}$ apresentaram as maiores taxas de germinação e contaminação, sendo 37,5\% e 29,17\% de germinação, respectivamente e $8,33 \%$ de contaminação. Houve influência do tempo de imersão em $\mathrm{H}_{2} \mathrm{SO}_{4}$ e do fungicida sobre a germinação e a desinfestação de L. pohlii.

Palavras-chave: Arnica; Desinfestação; Planta medicinal.
\end{abstract}

\footnotetext{
${ }^{1}$ Universidade Federal dos Vales do Jequitinhonha e Mucuri, Brasil. E-mail: carolturmalina@hotmail.com.

2 Universidade Federal dos Vales do Jequitinhonha e Mucuri, Brasil. E-mail: clara.ifmg.sil@hotmail.com.

${ }^{3}$ Universidade Federal dos Vales do Jequitinhonha e Mucuri, Brasil. E-mail: mirandatiton@gmail.com.
} 